\title{
Б. А. Садовской и Н. В. Гоголь: стилизация, пародирование, интерпретация
}

\section{N. V. Gogol' and B. A. Sadovskoy: Stylization, Parody, Interpretation}

\author{
Владислав Шаевич Кривонос \\ (Самара, Россия)
}

\section{Абстракт:}

В статье рассматриваются причины обращения Бориса Садовского к фигуре Гоголя в его прозе. Отмечается, что изображение писателя всякий раз стилизуется в соответствии с конкретными задачами, решаемыми в том или ином произведении. Впервые в роли персонажа Гоголь возникает в рассказе «Праздничный день поручика Матрадурова». Реконструируемая картина прогулок по Невскому проспекту не просто проецируется на гротескные фантазии Гоголя, но служит их пародийной копией. В рассказе «Из бумаг князя Г.» Садовской, продолжив ироническую игру с квазиисторической достоверностью, не только вписывает условную фигуру Гоголя в столь же условный мир прошлого, но и разрушает популярный в начале XX века миф о Гоголе. В повести «Кровавая звезда», где Гоголь выведен персонажем второго плана, его роль в сюжетных событиях, подчиненных действиям инфернальных сил, оказывается важной для понимания их скрытого смысла. В рассказе «Двойник» существенное значение приобретает эпиграф из повести Гоголя «Портрет». Автор статьи показывает, как Садовской, используя приемы ироничной стилизации, стремится рестраврировать строй мысли Гоголя.

\section{Ключевые слова:}

Садовской; Гоголь; стилизация; пародия; ироническая игра; художественная интерпретация 


\section{Abstract:}

The article discusses the causes of the appeal of Boris Sadovskoy to the figure of Gogol' in his prose. It is noted that the image of the writer is always styled in accordance with specific tasks that are solved in a particular work. Gogol appears for the first time in the role of a character in the story "Festive Day of Lieutenant Matradurov". The reconstructed picture of walks along Nevsky Prospekt is not just projected onto Gogol's grotesque fantasies, but serves as a parody of them. In the story "From the papers of Prince G." Sadovskoy, continuing the ironic game with quasi-historical certainty, not only fits Gogol's conditional figure into the equally conventional world of the past, but also destroys the myth of Gogol', popular at the beginning of the 2oth century. In the story "The Bloody Star", where Gogol' was portrayed as a supporting character, his role in the plot events, subordinated to the actions of the infernal forces, is important for understanding their hidden meaning. In the story "The Double" the epigraph from Gogol's novel "Portrait" acquires the important significance. The author of the article shows how Sadovskoy, using ironic stylization, seeks to restore the structure of Gogol's thought.

\section{Key words:}

Sadovskoy; Gogol stylization; parody; ironic game; artistic interpretation

Развернувшиеся в 1890-1900-е годы споры, затрагивавшие «личность Гоголя» и «смысл его творчества», порождали истолкования, «открыто порывавшие c „Гоголем XIX века“» ${ }^{1}$. Полемизируя с концептуальной схемой Мережковского, изложенной в его исследовании «Гоголь и черт», где «жалкая фигурка Гоголя» оказалась «распятой между двумя бесами - Чичиковым и Хлестаковым»², Садовской не принимает и традиционное представление об авторе «Мертвых душ», с чьим именем принято было связывать прежде всего развитие реалистического направления в русской прозе: «Всю позднейшую русскую литературу („беллетристику“) у нас привыкли выводить из Гоголя» ${ }^{3}$. Гоголь для него прочно укоренен в эпохе тридцатых годов, эпохе романтизма, где он занимает законное место рядом с Пушкиным, Жуковским и Языковым ${ }^{4}$. Сознание внутренней причастности к этой эпохе, во многом определившее

1 PAPERNYJ, V. M.: V poiskach novogo Gogolja. In: Svjaz’ vremen: Problemy prejemstvennosti v russkoj literature konca XIX - načala XX v. Moskva: Nasledije, 1992, s. 21.

2 SADOVSKOJ, B.: O romantizme u Gogolja. Vesy, 1909, № 4, s. 95.

3 Там же, с. 96.

4 Там же. с. 97. 
особенности тематики и сюжетики Садовского, признававшегося, что он «по природе романтик» ${ }^{5}$, объясняет причины обращения к фигуре Гоголя в его прозе. При этом изображение писателя всякий раз стилизуется в соответствии с конкретными задачами, решаемыми в том или ином произведении.

Впервые в роли персонажа Гоголь возникает в рассказе Садовского «Праздничный день поручика Матрадурова», где показано, как прогуливаются по Невскому проспекту «...знаменитые писатели, Греч и Булгарин, чиновник из департамента Иван Александрович Хлестаков, камер-юнкер Пушкин с женой, княгиня Лиговская с мужем и дочерьми, князь Петр Мещерский, граф Владимир Сологуб, тамбовский помещик Евгений Онегин...» ${ }^{6}$. Реконструируемая картина «балаганного прошлого», сплетенная «...из обманчиво достоверных исторических и мнимо недостоверных, фиктивных литературных фактов...» ${ }^{7}$, не просто проецируется на гротескные фантазии Гоголя, но служит их пародийной копией. А поручик, небрежно упоминающий, что проживает в одном доме с Гоголем, выступает пародийным подобием Хлестакова, когда хвалит писателя за верное описание Невского проспекта: «...гладко изображено, совсем Брамбеус!» ${ }^{8}$. Увиденный «глазами Матрадурова» ${ }^{9}$, Гоголь не случайно выглядит так, будто рожден воображением героя его комедии: «А вон и сам он выходит из кондитерской, сгорбился в своей шинели, крутит птичьим носом, высматривает кого-то. Забавник такой, - захочет, мертвого рассмешит» ${ }^{10}$. Столкнувшись затем «с длинноносым верхним жильцом» у «самых дверей своей комнаты», Матрадуров и ведет себя по-хлестаковски:

«- Ну что, брат? - снисходительно спросил поручик.

- Да что, брат, так как-то все, - возразил верхний жилец лениво» ${ }^{11}$.

Создавая в рассказе пародийно стилизованный образ исчезнувшего мира, где Гоголь встречается со своим потенциальным персонажем, Садовской пишет не столько по канве, сколько поверх гоголевских произведений; таков здесь его способ вживания в прошлое, от которого он иронически дистанцируется.

5 SADOVSKOJ, B.: Zapiski (1881-1916). In: Rossijskij Archiv: Istorija Otečestva v svidetel'stvach i dokumentach XVIII-XX vv.: Al'manach. [T.] 1. Moskva: Studija TRITÈ; Rossijskij Archiv, 1994, s. 147.

6 SADOVSKOJ, B.: Prazdničnyj den’ poručika Matradurova. Vesy, 1908, № 12, s. 19.

7 GOLYNKO, D.: «Bagatelle». Analiz tvorčestva Borisa Sadovskogo. <http://www.sadovskoi.ru/article/ bagatelle.html>. [online]. [cit. 22. 10. 2021].

8 SADOVSKOJ, B.: Prazdničnyj den’ poručika Matradurova. Vesy, 1908, № 12, s. 19.

9 BELONOGOVA, V. Ju.: Puškin i Gogol' v tvorčestve Borisa Sadovskogo. Vestnik Nižegorodskogo un-ta im. N. I. Lobačevskogo, 2014, № 2 (2), s. 19.

10 SADOVSKOJ, B.: Prazdničnyj den’ poručika Matradurova. Vesy, 1908, № 12, s. 19.

11 Там же, с. 22. 
В рассказе «Из бумаг князя Г.» Садовской, продолжив ироническую игру с квазиисторической достоверностью, помещает письмо к дяденьке Павла Г., племянника князя, описывающего, как при посещении московского дома Хомякова ему «пришлось нечаянно вступить в беседу» с присутствовавшим там «известным писателем Гоголем». Автор имитирует эпистолярную речь светского человека, рассказывающего, как он поначалу был задет «фамилиарностью» писателя, «вдруг» взявшего его «за пуговицу», и «несколько странным вопросом», касавшимся содержания «Одиссеи», и как был удивлен, что Гоголь «сам» за него «ответил». Если Гоголь «по его сочинениям» представлялся «надоедливо-шумным и сальным забавником», то теперь «своим тихим разговором и приятною улыбкою произвел» на молодого собеседника «впечатление хорошее». Тот даже готов причислить писателя «к людям comme il faut, хотя под отличным темно-красным жилетом» все-таки «разглядел у него нечистое белье» ${ }^{12}$.

Изображенная сцена, как отметил С. В. Шумихин в примечаниях к рассказу, явно перекликается с одним местом в воспоминаниях П. И. Бартенева, рассказавшего о неприятном впечатлении, которое производил Гоголь не на него одного, и передавшего разговор с писателем об эпизоде из «Одиссеи», который как раз не смог вспомнить герой рассказа, не успевший дочитать гомеровскую поэму до конца ${ }^{13}$. С. С. Сидорова-Бартенева, добавим, вспоминает, как дед ее, рассказывая о Гоголе, «морщился», что тот «был всегда небрежно и грязновато одет» ${ }^{14}$. Познакомившись с П.И. Бартеневым в 1906 году, Садовской часто навещал его и выслушивал рассказы о многочисленных его знакомых: «Странно было видеть человека, обедавшего у Чаадаева, говорившего с Гоголем об “Одиссее”» 15 .

Воспроизводя беседу с Гоголем, документально подтвержденную в мемуарных свидетельствах, Садовской говорит о предмете изображения «на чужом для него стилизуемом языке», исполняя роль «интерпретатора стилизуемой эпохи» ${ }^{16}$. Он не только вписывает условную фигуру Гоголя в столь же условный мир прошлого, но и разрушает (исключительно средствами пародийной

12 SADOVSKOJ, B.: Iz bumag knjazja G. 1826-1849. Vesy, 1909, № 6, s. 59-60.

13 SADOVSKOJ, B. A.: Lebedinyje kliki. Moskva: Sovetskij pisatel', 1990, s. 469.

14 Gogol'v vospominanijach, dnevnikach i perepiske sovremennikov. Polnyj sistematičeskij svod dokumental'nych svidetel'stv. Naučno-kritičeskoje izdanije. Izdanije podgotovil I. A. Vinogradov: V 3 t. T. 3. Moskva: IMLI RAN, 2012, s. 700.

15 SADOVSKOJ, B.: Zapiski (1881-1916). In: Rossijskij Archiv: Istorija Otečestva v svidetel'stvach i dokumentach XVIII-XX vv.: Al'manach. [T.] 1. Moskva: Studija TRITÈ; Rossijskij Archiv, 1994, s. 163.

16 GOLYNKO, D.: «Bagatelle». Analiz tvorčestva Borisa Sadovskogo. <http://www.sadovskoi.ru/article/ bagatelle.html>. [online]. [cit. 22. 10. 2021]. 
стилизации речи персонажа, чье представление о писателе кардинально изменяется после разговора с ним) порожденный позитивистским литературоведением «миф об иррациональной двойственности Гоголя, полностью созвучный символистскому мифу о Гоголе» ${ }^{17}$. Недаром Садовской предлагал «взглянуть на Гоголя просто» ${ }^{18}$. Именно так, просто, и взглянул в его рассказе на Гоголя простодушный московский студент.

Персонажем второго плана выведен Гоголь в написанной в 1919 году повести «Кровавая звезда», в которой слышны отголоски расхожего мнения, разделявшегося тогда Садовским, «о некоем заговоре мирового зла против России» ${ }^{19}$. Между тем роль писателя в сюжетных событиях, подчиненных действиям инфернальных сил, весьма значима для понимания их скрытого смысла. Мистифицированный образ Гоголя соседствует здесь с образами реальных исторических лиц, изображение которых также отвечает законам литературной мистификации. Это важно отметить, так как историческая конкретика в «Кровавой звезде», пропитанная исторической мистикой, тесно переплетается с фантастикой в духе произведений «неистового» романтизма, заполненных описанием разного рода тайн и ужасов, переводы которых пользовались популярностью в России 1830-х годов. «Кровавая звезда», несомненно, уходит корнями в массовую беллетристику этого десятилетия, адаптировавшую и разрабатывавшую соответствующие сюжеты и мотивы. Садовской, будучи внимательным читателем литературы такого рода, обыгрывает их и стилизует в свойственной ему манере, воссоздавая образ чужого языка, на котором он стремится рассказать читателю о фатальном ходе русской истории.

Главным злодеем в повести выступает «барон-дипломат из голландского посольства» ${ }^{20}$. Он появляется в костюме Мефистофеля на маскараде в Зимнем дворце, где его дочь Гета, следуя отцовскому плану, приступает к обольщению наследника, будущего императора Александра II. Вынужденный покинуть Россию, барон оказывается хранителем музея в аббатстве Сан-Донато, расположенном недалеко от Рима, которое посещает наследник и сопровождающие его Жуковский, наставник наследника, и «два юных сверстника: Алексис Толстой и Жозеф Виельгорский» ${ }^{21}$. Во дворце Наполеона наследник неожиданно встречается с баронессой, чьей красотой пленяются все, кроме Виельгорского,

17 PAPERNYJ, V. M.: V poiskach novogo Gogolja. In: Svjaz' vremen: Problemy prejemstvennosti v russkoj literature konca XIX - načala XX v. Moskva: Nasledije, 1992, s. 24.

18 SADOVSKOJ, B.: O romantizme u Gogolja. Vesy, 1909, № 4, s. 95.

19 ŠUMICHIN, S.: Boris Sadovskoj. Krovavaja zvezda. De Vizu, 1993, № 4 (5), s. 12.

20 SADOVSKOJ, B.: Krovavaja zvezda. De Vizu, 1993, № 4 (5), s. 17.

21 Там же, c. 23. 
безмолвствовавшего и не отходившего от наследника «ни на шаг» ${ }^{22}$. Поведение Жозефа предопределяет его участь: барон вдруг вручает ему письмо от отца, вызывающее его в Рим; письмо привез, по его словам, «какой-то музыкант или учитель, похожий на журавля», в котором Виельгорский узнает общего с Жуковским знакомого: «Его фамилия Гоголь» ${ }^{23}$. Следом, обеспокоенный внезапным отъездом Жозефа, отправляется в Рим в коляске барона, вызывающей демонические ассоциации (храпели «огромные кони», щелкавший на них «горбатый кучер свистал по-птичьи»), и Жуковский, чувствовавший, что туда толкает его «неодолимая сила» ${ }^{24}$. В Риме Гоголь сообщает ему об опасной болезни юноши, захворавшего еще дорогой, и о том, что отец его почему-то задержался с приездом: «Сдается, тут не обошлось без чертовщины» 25 .

Гоголь, выполняя просьбу Жозефа привести священника, убегает в посольство; в доме внезапно появляется аббат из Сан-Донато, потребовавший пустить его к больному, которого он считает католиком, чтобы причастить его не по православному обряду, как хотел Виельгорский, а по католическому, угрожая в случае отказа Ватиканом. Гоголю, вернувшемуся со священником, визит аббата кажется странным, поскольку аббатство Сант-Донато «давно упразднено»и «монастырь пустой»; кинувшись с Жуковским на «резкий крик» в спальне, они обнаруживают мертвого Жозефа, но исповедника не находят: «Гоголь крестился» ${ }^{26}$.

Тематически стилизуя описываемую эпоху, Садовской не стремится точно следовать реальным историческим фактам; он преобразует их так, как того требуют сюжетная логика и логика повествования. В действительности Виельгорский, соученик наследника, имевший с ним общих наставников, тяжело заболев, прибыл в Рим вместе с отцом, где встретился с Гоголем; там его навещали наследник и приехавший вместе с ним Жуковский ${ }^{27}$. Ю. В. Манн, сопоставляя свидетельства современников, подробно описывает предшествовавший кончине Виельгорского «эпизод неудавшегося обращения его в католичество», причем «решающую роль в несостоявшемся обращении сыграло тактичное поведение аббата Жерве», приглашенного княгиней

\footnotetext{
22 Там же, с. 24 .

23 Там же, с. 25 .

24 Там же.

25 Там же, с. 26.

26 Там же, с. 27.

27 MANN, Ju. V.: Gogol'. Kniga vtoraja. Na veršine: 1835-1845. [2-je izd., pererab. i dop.]. Moskva: RGGU, 2012, s. 215-217.
} 
3. А. Волконской, чье намерение, обнаруженное ею ранее «и в отношении Гоголя», вызывало у того «неодобрительное отношение» ${ }^{28}$.

В «Кровавой звезде» Виельгорский становится очередной жертвой барона, существа демонического, устраняющего всех, кто мог бы помешать его плану; обладая способностью к перевоплощению, он принимает облик аббата, сумев ввести в заблуждение автора «Людмилы». Гоголь единственный, что определяет его сюжетную роль, кто сразу заподозрил (не обошлось без чертовщины) вмешательство в судьбу Виельгорского нечистого духа; потому он и стал креститься, заметив исчезновение мнимого исповедника. Но его проницательность, подкрепленная художественным чутьем и опытом изображения инфернальных сил и их пагубных влияний, не могла, согласно логике мистического сюжета повести, спасти юного Жозефа, обреченного погибнуть, как обречены погибнуть наследник, которому Гета показывает, но отказывается объяснить мистическое «сочетание чисел», связанных с «мартовским знаком зодиака», а потом и Россия, о чем наследник уже не узнает, хотя баронесса, улыбаясь, и желает ему «дожить до 917 года» ${ }^{29}$.

В 1922 году в книге Садовского «Морозные узоры» появился фантастический рассказ «Анекдот»; в 1990 году он был опубликован по позднейшей рукописи с новым названием, «Двойник», и добавлением эпиграфа из «Портрета» Гоголя. В гоголевской повести важную роль играет мотив сна во сне; о ситуации перехода из одного сна в другой эпиграф и напоминает: «И вот он глянул к нему вновь за ширмы» ${ }^{30}$. Выбором эпиграфа Садовской, на что прямо указывает история героя, подчеркивает значимость подобных переходов для сюжетной организации рассказа.

Молодого беллетриста Озимовского незнакомка, называющая себя Временем, переносит с его согласия в Москву 1851 года, где он чувствует себя наблюдателем, замечающим и фиксирующим знаки и приметы навсегда ушедшего мира, и внезапно осознавшим, что его окружают «покойники» 31 . Герой, по его самоощущению, будто оказался на том свете, почему и засомневался вдруг, не покойник ли он сам. Между тем о событиях, к которым причастны интересующие его обитатели старой Москвы, в 1851 году еще живые, он знает куда больше, чем ведомо тем сейчас; среди них и автор «Мертвых душ», к которому Озимовский относится с особым пиететом. Возможность встретиться с Гоголем и определила, видно, выбор им и места, куда он решил

\footnotetext{
28 Там же, с. 219-221.

29 SADOVSKOJ, B.: Krovavaja zvezda. De Vizu, 1993, № 4 (5), s. 28.

30 SADOVSKOJ, B. A.: Lebedinyje kliki. Moskva: Sovetskij pisatel', 1990, s. 303.

31 Там же, с. 306.
} 
отправиться, и времени путешествия. Но вероятность подобной встречи, учитывая характер писателя, тяготившегося общением с незнакомыми ему людьми и избегавшего каких-либо разговоров с ними, выходила за границы фантастического допущения, почему она и не состоялась.

Ср.: «Поравнявшись с особняком, где скончался Гоголь, Озимовский вспомнил, что Гоголь теперь в Москве и, наверное, в этом доме. Ему сделалось жарко». Когда же, собравшись с духом, он «робко дернул звонок», то дверь ему «отворила старуха», сообщившая, что Николай Васильич ушел «к обедне», а «за ней выглядывал мальчик в куртке», который, как он подумал, направляясь в церковь, чтобы увидеть Гоголя, «через два месяца будет жечь „Мертвые души“». Беспокоясь, что, «пожалуй, и Гоголя не увидишь», Озимовский «все прибавлял, задыхаясь, шагу», но когда «подбежал он к церкви», то обнаружил, что обедня «только что отошла» и что «Гоголя не было». Пришлось идти назад, но мальчик «бойко ответил», что Николай Васильич не вернулся, и пригласил зайти «завтра», хотя видно было по лицу его, «что Гоголь дома» ${ }^{32}$.

Но вернемся к эпиграфу и проследим за логикой сновидческого кошмара Чарткова, которому кажется, что старик, вышедший из портретной рамы, «глянул к нему вновь за ширмы»; стиснув «всею силою в руке» сверток с золотом, за которым тот вернулся, он просыпается, спрашивая себя, не сон ли это был, «...но страшная живость явленья не была похожа на сон» ${ }^{33}$. Пробуждение, однако, оказывается мнимым: Чартков вновь просыпается во сне, чтобы перейти в новый сон. Когда же он действительно проснулся и вспомнил «весь свой сон», скорее похожий на «виденье», то ему стало казаться, «...что среди сна был какой-то страшный отрывок из действительности» ${ }^{34}$. Всякий раз иллюзия пробуждения сопровождает переход в другой сон, причем для Чарткова, вышедшего из состояния сонного морока, достоверность увиденного остается проблематичной. Показательно, что все, что происходит с ним далее, оборачивается сном наяву, который завершается безумием.

Посмотрим внимательнее, какими подробностями, приобретающими особое значение, если соотнести их с эпиграфом, адресующим к изображенному в «Портрете» сну во сне, обставлен в рассказе визит героя к Гоголю. От мысли, что он может увидеть Гоголя, ему «сделалось жарко», так что, оробев, он не сразу решился дернуть звонок: “Точно во сне”». На вопрос, прозвучавший из-за двери, он «долго не мог ответить», поскольку ему показалось, что он «просто бредит» или, может, «болен», что «сейчас проснется»; когда, не застав

32 Там же, с. $305-306$.

33 GOGOL', N. V.: Polnoje sobranije sočinenij: V 14 t. Moskva-Leningrad: AN SSSR, 1938. T. 3, s. 90.

34 Там же, с. 92 . 
Гоголя дома, он отправился в церковь, то почувствовал, переживая странное состояние, заставившее страшиться чего-то непонятного (подобного рода страх испытывает во сне и Чартков), «что это не сон»; в этом он убеждает себя, наблюдая за происходящим на площади и улицах: «Нет, это не сон» ${ }^{35}$. Однако граница между сном и явью по-прежнему представляется Озимовскому зыбкой; перенесенный в прошлое, он ощущает себя в Москве 1851 года персонажем длящегося сновидения, где возникают, сменяя друг друга, какие-то отрывки из действительности, поражающие страшной живостью явленья, но выйти из которого он не может.

Новый поворот сюжета вновь отсылает к сновидческим картинам гоголевской повести. Чартков видит во сне, как старик выходит из рамы портрета; дальнейшее повествование (во второй части «Портрета») подтверждает, что это действительно было виденье, а не оптическая иллюзия. Озимовскому, сидящему в трактире, кажется, будто оживает тень на стене; отделившись от стены, она превращается в его двойника, в «объятьях» которого он «растворился» ${ }^{36}$. Фантастичность сцены мотивирована жанром рассказа, но вероятность того, что героя, видящего ожившую тень, обманывает чувство зрения и что двойник есть порождение его расстроенного сознания, тоже не отменяется. Рационалистические мотивировки происходящего замещают у Садовского гоголевскую портретную мистику; изображаемое утрачивает принципиально значимое для гоголевского повествования онтологическое измерение.

Финал рассказа выражает самоиронию автора, вступившего в область гоголевских снов. Состояние Озимовского, «больного человека», живущего, как ему кажется, «в стародавние времена» ${ }^{37}$, порождает сомнения, не привиделось ли пациенту психиатрической клиники все, что будто бы случилось с ним, не сновидческий ли это бред. Может, не умея отличить сон от яви, он из одного сна, когда одно мнимое пробуждение сменялось другим, просто переходил в следующий, то есть из настоящего времени в прошлое, пока не проснулся, состарившись и впав в слабоумие, в Москве будущего, где историческую мистику прежней Москвы, условно говоря, гоголевской, вытеснил механический прогресс, каким его представляет себе квазинаучная фантастика.

Если в лирике Садовской стремился «реставрировать строй мысли» поэзии Фета ${ }^{38}$, то в «Двойнике» он попытался реставрировать строй мысли Гоголя.

35 Там же.

36 Там же, с. 307.

37 Там же, с. 308.

38 BOGOMOLOV, N. A.: Poèty vne tečenij i grupp: Vladislav Chodasevič, Georgij Ivanov, Marina Cvetajeva $i d r$. Russkaja literatura rubeža vekov (1890-je - načalo 1920-ch godov). Kn. 2. Moskva: IMLI RAN; Nasledije, 2001, s. 657. 
Косвенно на это указывает желание героя непременно увидеться с Гоголем, хотя осталось неизвестным, зачем все-таки он добивался этой встречи. Между тем явно не случайным был выбор для героя фамилии Озимовский, отсылающей к вышедшему в 1915 году (согласно авторской датировке, это и год написания рассказа) сборнику статей Садовского, посвященных современной литературе, «Озимь». Озимовский предстает скрытым (стилизованным и пародийным) двойником автора «Озими», который с Гоголем в своем рассказе встретился.

\section{Литература:}

BELONOGOVA, V. Ju.: Puškin i Gogol’ v tvorčestve Borisa Sadovskogo. Vestnik Nižegorodskogo un-ta im. N. I. Lobačevskogo, 2014, № 2 (2).

BOGOMOLOV, N. A.: Poèty vne tečenij i grupp: Vladislav Chodasevič, Georgij Ivanov, Marina Cvetajeva $i$ dr. Russkaja literatura rubeža vekov (1890-je - načalo 1920-ch godov). Kn. 2. Moskva: IMLI RAN; Nasledije, 2001.

GOGOL', N. V.: Polnoje sobranije sočinenij: $V{ }_{14} t$. Moskva-Leningrad: AN SSSR, 1938. T. 3 .

Gogol' v vospominanijach, dnevnikach i perepiske sovremennikov. Polnyj sistematičeskij svod dokumental'nych svidetel'stv. Naučno-kritičeskoje izdanije. Izdanije podgotovil I. A. Vinogradov: V 3 t. T. 3. Moskva: IMLI RAN, 2012.

GOLYNKO, D.: «Bagatelle». Analiz tvorčestva Borisa Sadovskogo. <http://www. sadovskoi.ru/article/bagatelle.html>. [online]. [cit. 22. 10. 2021].

MANN, Ju. V.: Gogol'. Kniga vtoraja. Na veršine: 1835-1845. [2-je izd., pererab. i dop.]. Moskva: RGGU, 2012.

PAPERNYJ, V. M.: V poiskach novogo Gogolja. In: Svjaz' vremen: Problemy prejemstvennosti v russkoj literature konca XIX - načala XX v. Moskva: Nasledije, 1992.

SADOVSKOJ, B.: Iz bumag knjazja G. 1826-1849. Vesy, 1909, № 6.

SADOVSKOJ, B.: Krovavaja zvezda. De Vizu, 1993, № 4 (5).

SADOVSKOJ, B. A.: Lebedinyje kliki. Moskva: Sovetskij pisatel', 1990.

SADOVSKOJ, B.: O romantizme u Gogolja. Vesy, 1909, № 4 .

SADOVSKOJ, B.: Prazdničnyj den’ poručika Matradurova. Vesy, 1908, № 12.

SADOVSKOJ, B.: Zapiski (1881-1916). In: Rossijskij Archiv: Istorija Otečestva v svidetel'stvach i dokumentach XVIII-XX vv.: Al'manach. [T.] 1. Moskva: Studija TRITÈ; Rossijskij Archiv, 1994.

ŠUMICHIN, S.: Boris Sadovskoj. Krovavaja zvezda. De Vizu, 1993, № 4 (5). 


\section{About the author}

\section{Vladislav Shaevich Krivonos}

Samara State Social and Pedagogical University, Faculty of Philology, Department

of Literature, Samara, Russia

vkrivonos@gmail.com

https://orcid.org/0000-0001-8138-0057 
